\title{
Giant hydronephrosis secondary to ureterocele with duplex system in adults: Report of a case
}

\author{
Andrea Solinas, Luca Cau, Massimiliano Fanari, Ignazio Flaviani, Francesco Manca, Maurizio Melis \\ Department of Surgery, Urology Unit, ATS Sardegna - ASSL Carbonia, Ospedale Sirai, Carbonia, Italy.
}

\begin{abstract}
Summary
Giant hydronephrosis in adults is a rare entity. It is defined as an extensive dilatation of the pyelocaliceal cavities occupying a large part of the abdominal cavity. Giant hydronephrosis is usually due to pelvi-ureteric junction obstruction and is usually diagnosed in children and infants. Ureterocele, which is a cystic dilatation of the terminal ureter, often drains the upper part of the kidney in patients with a duplex system. Massive hydronephrosis in a patient with duplex system and obstructive ureterocele was described by Aeron et al. in 2017. A thorough search of the major medical databases disclosed that no other cases have been reported since. We describe a second case of unilateral complete duplex system with ureterocele and massive hydronephrosis of the upper moiety in an adult man with intermittent abdominal pain associated with constipation and a decrease in appetite. The renal function of the left kidney was $8 \%$ of total function by radionuclide renal scan. The patient subsequently underwent left laparoscopic nephrectomy.
\end{abstract}

KEY WORDS: Massive hydronephrosis; Ureterocele; Duplex system; Nephrectomy.

Submitted 29 April 2020; Accepted 6 June 2020

\section{INTRODUCTION}

Ureterocele is a cystic dilatation of submucosal distal ureter. It is rare in adults but presents a higher incidence in infants and young children. Ureterocele usually affects the upper moiety in case of complete duplication of the pelviureteric system and presents as abdominal pain and infection $(1,2)$. Massive hydronephrosis in adults is a rare entity and is easy to be misdiagnosed. It is defined as an extensive dilatation of the pyelocaliceal cavities occupying a large part of the abdominal cavity. In 1939 Stirling defined massive hydronephrosis as the presence of more than $1000 \mathrm{~mL}$ or $1.6 \%$ of body weight of fluid in the renal collecting system or the involvement of five vertebral heights. The aim of this paper is to present the second case of a massive hydronephrosis in an adult male affecting the duplex system associated with ureterocele.

\section{Case report}

A 63-year-old man with a history of left lumbar pain which had not been investigated was referred to our urology unit with an abdominal palpable mass and pain. He had diffuse abdominal pain, persistent constipation and a decrease in appetite but no urological symptoms or signs or fever. He had no history of hematuria or urinary tract infection. Clinical examination showed an asymmetric abdominal palpable mass with a smooth surface.

The mass extended from the left lumbar region to the pelvic region crossing the midline. Laboratory blood investigations were unremarkable. Ultrasound showed fluid-filled mass occupying all left abdominopelvic region and pressing the digestive structures. Computerized tomography revealed massive hydronephrosis of the left upper pole moiety, measuring around $28 \times 15 \times 17 \mathrm{~cm}$, with normally enhancing renal parenchyma at the region of lower pole (Figures 1,2). Pelvic section revealed dilated and tortuous upper pole moiety ureter with cystic focal dilatation in its submucosal part as it entered the bladder suggestive of ureterocele (Figure 3).

Radionuclide renal scan showed a hydronephrotic left kidney with decreased global glomerular filtration rate of the left side and overall impaired function of the left kidney (8\%). Radionuclide renal scan (Figure 4) documented a marked reduction in the size of the left kidney and poor parenchymal uptake in the corticomedullary phase, followed by delayed excretion, reflecting a reduced pyelocalyceal function. The left curve was considerably lower than the right and showed marked phase delay. The total glomerular filtration rate was $63.2 \mathrm{~mL} / \mathrm{min}$, $58.2 \mathrm{~mL} / \mathrm{min}$ (92\%) in the right kidney and $5 \mathrm{~mL} / \mathrm{min}$ (8\%) in the left. The patient underwent complete endoscopic excision of the ureterocele for decompression of the system.

Complete endoscopic excision of the ureterocele exposed a wide gaping ureteral meatus. Retrograde pyelography was not performed nor was a stent inserted. In line with Weigert-Meyer rule, another ureteral meatus, draining the lower moiety, was detected superolateral to the first. The next day an abdominal ultrasound scan, performed with the bladder catheter in situ, revealed complete resolution of the hydronephrosis of upper pole moiety and collapse of the ureterocele. The ultrasound scan performed after catheter removal demonstrated that the hydronephrosis had formed again, indicating the presence of ureteral reflux, which was demonstrated by a micturating cystourethrogram in the upper tract but not in the lower moiety or in the right kidney. Owing to the poorly functioning left kidney a left laparoscopic nephrectomy was performed about 3 months after ureterocele excision. Post-operative suites were simple and the 
Figure 1.

Abdominal CT scan in coronal and sagittal view showing giant hydronephrosis of the left upper pole moiety occupying almost the whole abdomen with normal renal parenchyma in the

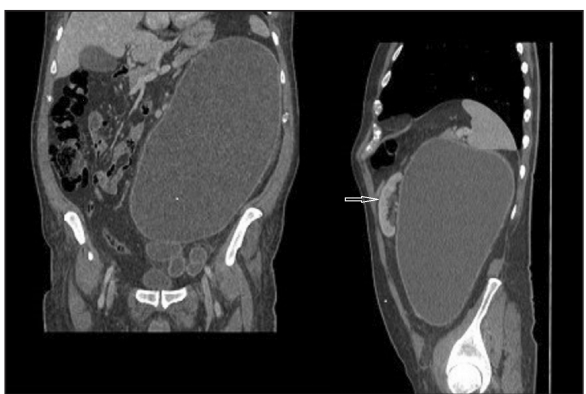
region of lower pole (white arrow) dislocated by hydronephrosis and dilated tortuous upper pole moiety ureter.

Figure 2.

Contrast-enhanced abdominal CT scan showing giant hydronephrosis of the left upper pole moiety in axial view with

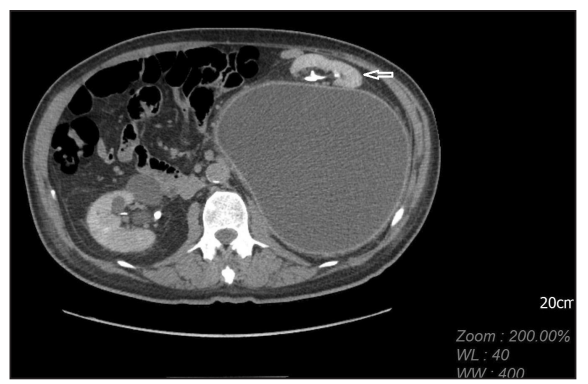
normal renal parenchyma at the region of lower pole (white arrow) dislocated by hydronephrosis.

Figure 3.

Contrastenhanced abdominal CT scan.

Pelvic section revealing dilated upper moiety ureter with

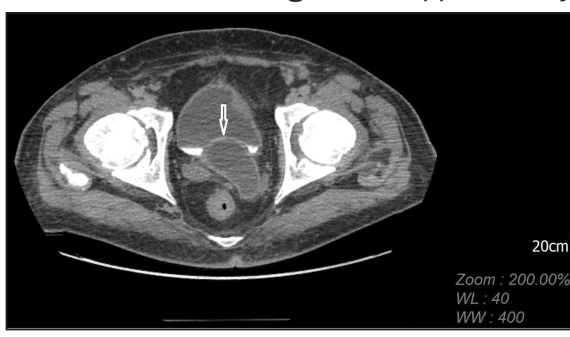
cystic focal dilatation in its submucosal part as it enters the bladder (white arrow). patient was discharged uneventfully on the $4^{\text {th }}$ postoperative day. After three months the patient is asymptomatic and has normal renal function. Histology confirmed hydronephrosis, diffuse compression atrophy of the renal parenchyma and chronic interstitial nephritis.

\section{Discussion}

In 1939 Stirling defined massive hydronephrosis as the presence of more than $1000 \mathrm{~mL}$ or $1.6 \%$ of body weight of fluid in the renal collecting system. In 1979 Crooks et al. defined radiographic criteria for massive hydronephrosis as the kidney occupying the hemi-abdomen which also meets or crosses the midline and has a height of about 5 vertebral bodies (3). With higher standards of medical care massive hydronephrosis is now a rare urological entity, occurring predominantly in children. The commonest cause is congenital pelvi-ureteric-junction obstruction which occurs in $80 \%$ of cases (4) followed by stones. Other less common causes include congenital ureteral narrowing, ureteropelvic tumors, trauma, renal ectopia, retroperitoneal fibrosis, obstructive megaureter (5), ureteric atresia, polar or aberrant vessels. More than 600 cases have been reported worldwide to date, most of them in the last 15 years (6). Massive hydronephrosis is a slowly progressive disease and a huge abdominal mass or distended abdomen may be the only sign. Patients may remain asymptomatic until late phase. Its wide differential diagnosis includes intraperitoneal cysts (mesenteric or choledochal), retroperitoneal cysts (renal or adrenal or pancreatic pseudocysts), pseudomixoma, ovarian cysts/tumors, ascites (7). It usually presents with vague symptoms such as fatigue, dyspepsia or nausea, mild diffuse abdominal pain or uncomfortable feeling and persistent constipation, urinary tract infection, renal insufficiency or hematuria after trauma in adults (5). Ureterocele is a cystic dilation of the distal ureter. It is a congenital anomaly associated with other anomalies such as a duplicated system and other diseases. Most of the ureteroceles are diagnosed in utero or during the postpartum screening for congenital malformations (1) while in adult patients it is rare and usually asymptomatic.

Ureterocele can be associated with a single or a duplex system, the latter being more common. Most adult ureteroceles are in single system, intravesical and located on the trigone of bladder. Ureterocele in a duplex system most commonly involves the upper pole moiety and hydronephrosis is usually due to obstruction at the lower end.

\section{Figure 4.}

Radionuclide renal scan depicting a reduced size and a markedly reduced parenchymal uptake in the left kidney. The left nephrographic curve is considerably lower than the contralateral curve and shows marked phase delay. 
According to Weigert-Meyer rule, in patients with a duplex system the upper moiety ureter drains into the bladder more medial and inferior to the lower moiety ureter.

This was also the case of our patient. Ureterocele causing obstruction in adults is uncommon. Even uncommon is the association of the massive hydronephrosis with the duplex system in adults. Until now, there is only one case of giant hydronephrosis of upper pole moiety in a duplex system associated with ureterocele reported in the literature (1). The management of ureterocele is controversial, which is related to the type of presentation and postoperative morbidity. Endoscopic approach, for short operation time and acceptable outcomes, is considered as the gold standard for intravesical ureterocele. The goals of endoscopic techniques are to decompress the obstructed system minimizing the incidence of postoperative reflux (1). Other procedures like upper polar nephrectomy or ureterocele excision and common sheath reimplantation are required on the basis of the renal function of an involved moiety, persistent obstruction or vesico-ureteral reflux of the upper tract and occurrence of new vesico-ureteral reflux post-procedure. In our case, endoscopic ureterocele resection was successful in decompressing the dilated system and ureterocele but in consideration of persistent vesico-ureteral reflux of the upper tract and owing to the poorly functioning left kidney we decided to perform a laparoscopic nephrectomy. The interest of our case lies in the combination of rare adult giant hydronephrosis and two uncommon abnormalities: duplex system and obstructive ureterocele.

\section{Conclusions}

The most important aspect of management is early diagnosis with accurate preoperative delineation of anatomy of the affected kidney. It is still not easy to differentially diagnosis. It usually presents with vague symptoms such as fatigue, dyspepsia or nausea, urinary tract infection, renal insufficiency or hematuria after trauma in adults
(8). It is not likely to consider a massive hydronephrosis diagnosis firstly. Nowadays, diagnostic instruments such us CT scan and ultrasonography have facilitated an accurate diagnosis of hydronephrosis. For this reason, the clinician and radiologist could readily diagnose and provide appropriate therapy. Adult obstructing ureterocele is uncommon, while adult massive hydronephrosis combined with a duplex system is highly uncommon.

The case of our patient, who exhibited all three abnormalities, deserves to be shared with the scientific community.

\section{REFERENCES}

1. Aeron R, Sokhal AK, Kumar M, Sankhwar S. Giant hydronephrosis in a case of ureterocele with duplex system: an entity yet not reported. BMJ Case Rep. 2017. DOI:10.1136/bcr-2017-221379.

2. Merlini E, Lelli Chiesa P. Obstructive ureterocele-an ongoing challange. World J Urol. 2004; 22:107-14.

3. Crooks KK, Hendren WH, Pfister RC. Giant hydronephrosis in children. J Pediatr Surg. 1979; 14:844-50.

4. Yang WT, Metreweli C. Giant hydronephrosis in adults: the great mimic. Early diagnosis with ultrasound. Postgrad Med F. 1995; 71:409-12.

5. Solinas A, Pau AC, Ayyoub M, Frongia M. Primary obstructive megaureter in adults: management strategy in a young woman. Arch Ital Urol Androl. 2010; 82:192-4.

6. Guanghui Hu, Min luo, Yunfei Xu. Giant hydronephrosis secondary to ureteropelvic junction obstruction in adults: report of a case and review of literature. Int J Clin Exp Med. 2015; 8:4715-17.

7. Kaura KS, Kumar M, Sokhal AK et al. Giant hydronephrosis: still a reality!. Turk J Urol. 2017; 43:337-44.

8. Kaya C, Pirincci N, Karaman MI. A rare case of an adult giant Hydroureteronephrosis due to ureterovesical stricture presenting as a palpable abdominal mass. Int Urol Nephr. 2005; 37:681-83.

\section{Correspondence}

Andrea Solinas, MD (Corresponding Author)

sol.andrea@tiscali.it

Luca Cau, MD

luca.cau@atssardegna.it

Massimiliano Fanari, MD

massimiliano.fanari@atssardegna.it

Ignazio Flaviani, MD

ignazio.flaviani@atssardegna.it

Francesco Manca, MD

franc.manca@atssardegna.it

Maurizio Melis, MD

maurizio.melis@atssardegna.it

S.C. Urologia, ATS Sardegna - ASSL Carbonia

Ospedale Sirai, Via Ospedale, 09013 Carbonia (Italy) 